\title{
Application of the Data-Driven Educational Decision-Making System to Curriculum Optimization of Higher Education
}

\author{
Yufan Du (iD) ${ }^{1,2}$ \\ ${ }^{1}$ Exchange and Cooperation Department, Guangdong Polytechnic of Industry and Commerce, Guangdong, China \\ ${ }^{2}$ School of Education, South China Normal University, Guangdong, China \\ Correspondence should be addressed to Yufan Du; 0021092@yzpc.edu.cn
}

Received 12 November 2021; Revised 21 November 2021; Accepted 25 November 2021; Published 4 January 2022

Academic Editor: Narasimhan Venkateswaran

Copyright (C) 2022 Yufan Du. This is an open access article distributed under the Creative Commons Attribution License, which permits unrestricted use, distribution, and reproduction in any medium, provided the original work is properly cited.

\begin{abstract}
Advancement in information technology has given a tremendous change in the education system. The traditional classroom education system is slowly getting transferred to the modernized system. In this conversion, the students choose to select the courses to learn in their higher education. The selection will aid the student in learning advanced technologies through theoretical and practical methods. In this research work, a data-driven educational decision-making system with the support of a course curriculum is analyzed with student's response after the course. The educational decision-making is implemented with the help of the mobile learning technology designed and maintained by the colleges and universities. For performing the analysis, the student response dataset is given as input to the fuzzy logic system to perform the analysis. The research shows that mobile learning technology with the fuzzy logic system has provided better decision-making analysis to curriculum optimization for the student and teachers.
\end{abstract}

\section{Introduction}

In the past, teachers and school systems have collected and used data in one way or another, whether in the form of a grade book to track progress and calculate final grades or standardized test results to gauge district-wide accomplishment. Technology has made it easier for educators to use data and analytics in their classrooms. When delivering lessons, teachers can now employ tools to monitor their students' understanding in real-time or provide them with the outcomes of homework assignments before strategizing future studies [1]. Using online platforms, teachers can create or choose films with questions attached that can be assigned as homework. Tracking who watched and how well they did is done via the data analytics portion of the platform. Based on the findings, teachers can use this information to design their classes, group students, scaffold learning activities, and differentiate instruction [2]. As a bonus, it provides valuable information about which students would benefit from further assistance and who might be most suited to lead class discussions.
Teachers' responsiveness to pupils, time savings, and relevance can all be improved by using data-driven decisionmaking in education [3].

Additionally, the use of data and analytics can help solve educational disparities. As the financial gap widens, the number of children who are denied equitable educational chances climbs. By examining data, researchers can determine how factors like diet, pre- $\mathrm{K}$ programs, and parental participation affect achievement inequalities [4]. If interventions and policies positively or negatively impact graduation rates and the achievement of key learning milestones, we can evaluate them. Education leaders can use this information to implement and push for policies that will help eliminate achievement gaps more effectively [5]. EPI used data from the National Center for Education Statistics to examine two kindergarten classes ten years apart in age. Both groups' reading and numeracy skills were assessed to evaluate how they compared to suitable levels for kindergarteners. Pre-K participation and "whole child" approaches to schooling were also examined in the study [6]. 
Accordingly, the authors gleaned crucial information regarding strategies to help low-income youngsters become more ready for school and close achievement gaps [7]. Educators use a range of methods to make data-driven judgments. Teachers use data as a part of their reflective teaching. After observing students and drawing conclusions from what they see, they alter their instruction accordingly. Often, the fixes are made at the moment. When a teacher notices that a student has difficulty reading, they may give a more uncomplicated reading assignment tailored to her ability level [8]. Long-term changes in teaching methods may also be necessary in some cases. For instance, a teacher may implement new student-centered activities after getting input from a supervisor.

Schools use collaborative approaches to make data work in their favor. Teachers and administrators may use standardized test scores, attendance statistics, and behavioral data to judge their schools. Processes such as this can help catch pupils falling between the cracks and indicate areas where the curriculum needs to be improved [9]. To establish a foundation of knowledge about their students, educators should consult historical data. Using data from the past, teachers may see what kids have learned and where they have fallen short of expectations. Teachers can use this data to map out what skills to cover next and where their students need extrasupport [10]. Many school systems use standardized tests to determine if a pupil is advanced, proficient, essential, or below basic in their abilities. Teachers can use this information to determine why some classes in the same grade level are not making as much progress as others [11]. Teachers can use this information to aid pupils with special needs. When pupils are below basic level, teachers may place them to the front to have ready access to additional support. Alternatively, they could give more challenging activities to pupils who have already achieved a certain level of proficiency [12]. When evaluating student achievement, educators should use a variety of datasets. An exam at the end of a unit is not the only way to learn about students' skills, weaknesses, and preferences [13]. Thumbs up/thumbs down check-ins are a simple formative evaluation that teachers can use to gauge student understanding and participation quickly. Teachers can learn a lot about their students by observing their interpersonal and social successes. This information can be used better to arrange students for joint work or lesson planning [14].

Teachers need to figure out how to use the data they collect. When it comes to answering a particular question, specific data can be helpful, but not when it comes to another [15]. This question-answering could include data that shows that a specific set of kids come from a lower socioeconomic status. That may explain why certain students struggle academically, but it does not explain why they performed poorly on an exam. Teachers can better identify and respond to problems when they understand how data can and cannot be used. If, for example, an instructor blames bad test scores on a student's socioeconomic status, they will be unable to identify the root cause of the problem [16]. With the emergence of modern technology, data-driven decision-making in education has never been easier. Teachers can now use several free and low-cost data tools to uncover hidden patterns and insights or organize and keep their data accessible for research [17]. A teacher's record-keeping instrument has traditionally been the grade book. There are several valuable features available with today's electronic grade books, including connecting standards to assignments, making it easier to assess a student's proficiency in specific subject areas, and analyzing student achievements [9]. Teachers can use a variety of data to aid in lesson planning. Teachers must consider their pupils' skill deficits and how many students are proficient, essential, or below basic. At the beginning of the school year, teachers may ask their pupils their favorite topics and activities [18]. Teachers can use the survey results to tailor their classes to the interests of their students and incorporate their preferred methods of instruction into the lesson plan. When teachers have access to the pertinent data, they can determine what factors are responsible for a student's success or failure. Teachers can come up with solutions to these problems once the sources of the issues have been identified [19]. For example, teachers can learn a great deal about a student's understanding by examining their homework grades and test scores, which can provide valuable information. Teachers can then use this information to create workouts and activities that target students' weak areas and help them improve their grades [20].

Moreover, the number of students receiving higher education is vast, and the categories of higher education courses are increasingly perfect. This perfection causes the data generated by the higher education ecosystem to increase dramatically, but data's storage, extraction, analysis, and utilization are not optimistic [21]. The increasing development of the curriculum makes it imperative to apply datadriven decision support systems to curriculum optimization. Therefore, the data-driven educational decision-making system is used to research the curriculum optimization of higher education [22]. A system that integrates the curriculum optimization of higher education based on the original educational decision-making system is constructed. A new model for the curriculum optimization of higher education is established. The curriculum optimization report and questionnaire are used to investigate, summarize, and analyze the curriculum optimization system of higher education. The study results show that the data-driven educational decision-making system affects the curriculum optimization of higher education [23]. It is concluded that the data-driven education decision-making system is more effective than the traditional optimization method in curriculum optimization of higher education [24]. In the context of machine learning in the new era, this research focused on data-driven educational decision-making systems for curriculum optimization of higher education.

\section{Proposed Architecture}

In Figure 1, teacher and system admin play a significant role in the data-driven educational decision-making system in higher education in this architectural diagram. With this decision-making system, students are allowed to learn new trending technology-related courses in their higher 


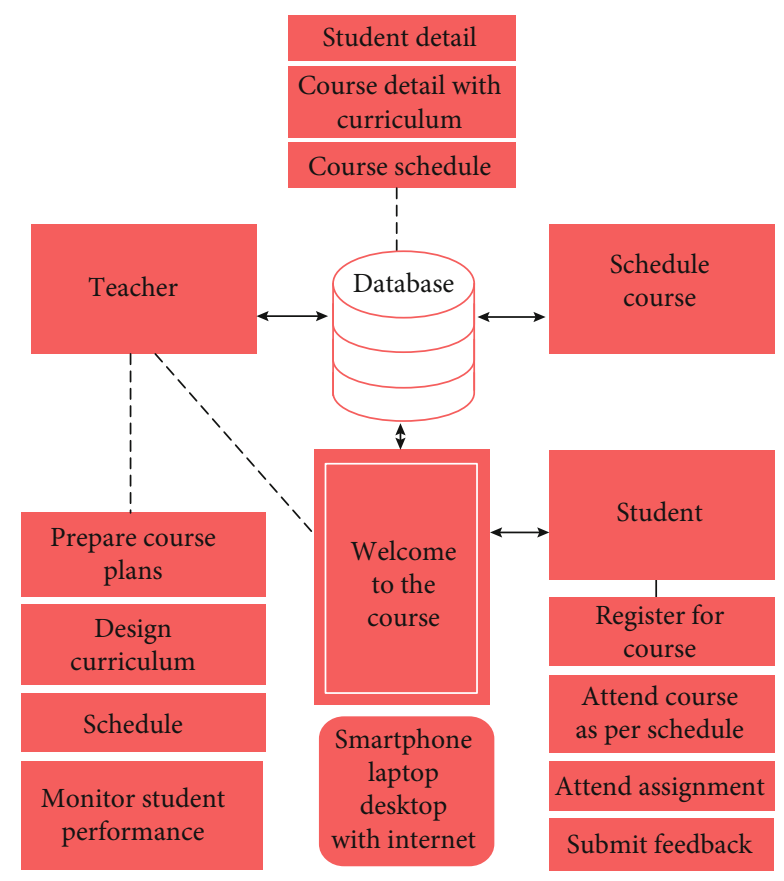

FIgURE 1: Architecture diagram of the proposed data-driven decision making system.

education. Teachers will have a challenging role in designing the curriculum for the courses, creating a schedule for the students to attend the classes, and making the course successfully in a given timeline. The courses may be theoretical or practical courses with varying credit points. The teachers of the colleges or universities will provide prior instruction and the basic concepts about the courses with conditions of selection to the students. According to student's selection of the courses and the schedule, the system administrator will conduct a feasibility study. The final decision about the courses and their schedule will be updated on the college or university website and their database. The system administrator will notify the update through a mobile application to the students and teachers which the college or university designs. Throughout the course completion, system administrators have to be made available to update the students regarding the courses and changes in schedule. The data stored in the database will be made accessible to the students through mobile learning technology. Also, when there is any feedback from the students, the teachers have to make appropriate decisions. Data-driven education is a process in which the students can choose the subjects they are willing to learn in their higher education. Depending on student's feedback, the teacher will decide whether to modify the curriculum for the next batch of students.

\section{Methods and Data}

Online courses became an important learning method for college students during the recent academic period.

Nevertheless, in digital training model, the studentteacher interaction is not direct as in classrooms but can accurately place students' abilities. There are numerous issues and limitations, such as one evaluation, for illustration, the indifference of process evaluation, and the use of a simplified evaluation report. As a result, how an online course teaching evaluation method should be built and whether the evaluation mechanism should be used effectively becomes an urgent issue. The online course assessment optimization framework based on process evaluation is implemented based on big data analysis of online learning evaluation data. The optimization of online learning evaluation is analyzed using machine learning and collaborative filtration technology on information from online course evaluations and student responses. It entails improving teacher teaching as well as student learning performance. The data testing shows that the fuzzy logic algorithm will provide an optimal evaluation methodology, enhance the integrity of students' learning, and increase online courses' efficiency.

A collection of variables containing specific factors that contribute to a complex problem is also based on the composite framework, with factors at every level, especially in comparison, and ranked in order of importance. Finally, in the decision-making problem, the strength of each critical value is determined.

A decision matrix is still a decision-making tool that assesses and prioritizes a range of suggestions. The team creates a list of evaluation criteria but then compares each option to such standards. This type of evaluation variant is an L-shaped matrix variant. To establish a decision matrix, kind of each compare row, as well as generate $S=\left(s_{i j}\right) n *$ $w$, in which $n$ represents the number of related pairs of responses. AHP then appears to confirm the $-e$ evaluation strength training. To ensure the highest eigenvector $Q_{\max }$ and also the corresponding eigenvalues $w$, solve the eigenvalue for such position of the decision matrix $S$. The findings of the calculation process are sorted at various levels based also on sequence of extracted features. Ultimately, the decision matrix's stability check must compute the consistency index $D M=\left(Q_{\max }-n\right) /(n-1)$. The random reliability value satisfies the following criteria: the ratio Error Ratio $=(D M /$ $I)<0.1$. The decision matrix is thought to meet requirements of consistency. Alternatively, the decision matrix must be modified in order to meet the conformance requirement.

Generate the following evaluation attributable to a number as in

$$
D=\left[D_{1}, D_{2}, \cdots, D_{5}\right],
$$

where $D$ denotes the five possible score stage vectors used to express the respective score. The periodic fashion standard could be written as in

$$
F=\left[f_{1}, f_{2}, \cdots, f_{5}\right]
$$

Evaluate $p_{i j}$ fuzzy matrix. Assess the $o_{i j}^{(t)}$ as the value of $p_{i j} . o_{i j}^{(t)}$ is a measurement value with the letter $t . o_{i j}^{(t)}$ is a 
member function $(t)$. The following is $o_{i j}^{(t)}$ of

$$
o_{i j}^{(t)}=\frac{\max o_{i j}^{(t)}-o_{i j}^{(t)}}{\max o_{i j}^{(t)}-\min o_{i j}^{(t)}} .
$$

Define $p_{i j}$ fuzzy evaluation vector as $U_{i}$ as in

$$
U_{i}=\omega_{i} Q_{i}\left(u_{1}, u_{2}, \cdots, u_{5}\right) .
$$

The fuzzy verification assessment the vector of $p$ is denoted as $V$, and it can be calculated using the below equations.

$$
\begin{gathered}
V=w U=\left(v_{1}, v_{2}, \ldots . ., v_{3}\right), \\
g_{t}=\min 1, \sum_{j=1}^{u} a_{j} p_{j t},
\end{gathered}
$$

where $t=1,2, \cdots, m$ creates a fuzzy evaluation model, and also, the requirement to ensure could be determined using the below equation.

$$
L=F U^{t} .
$$

There at upsides and downsides of using sentiment classification $L$ filtering method and information modeling method to support various exercise suggestion, a personalized and then integrates equivalent student information and performs collaborative filtering suggestion. The suggestion result takes into account both students' having developed and the generalization of group students' learning status, which improves the descriptive and correct information.

The cosine correlation between the vectors $u_{i}=s_{1}, s_{2}, \cdots$ $s_{n}$ and $u_{j}=a_{1}, a_{2}, \cdots, a_{n}$ is decided by the understanding horizontal vector matrix $u$. Assume $u_{i}$ and $u_{j}$, and determine the similarity measure between $u_{i}$ and $u_{j}$ as in

$$
\cos (\theta)=\frac{b_{i} * b_{j}}{\left\|b_{i}\right\| *\left\|b_{j}\right\|} .
$$

By classifying the similarity measure, a student for whom cosine similarity is higher than almost any threshold (e.g., 0.9 ) is chosen as an associate example. A finished workout score variable for goal student $I$ is expected using the following equation.

$$
h_{i}=\rho * b_{\mathrm{i}}+(1-\rho) *\left(M_{i}\right)^{\mathrm{avg}} .
$$

The parameter $\rho$ adjusts the fraction of differences in students' level of knowledge to the prevalent knowledge level between students. The recommended value of $\rho$ is $[0,1]$. As the significance of increases, $\rho=0, h_{i}$, so does the effect on student's educational knowledge level, especially when $f i$ seems to be the estimate of student's level of knowledge minus student's educational status. When $z=1, h_{i}$ is the variable of specific experience, $h_{i}$ is the level variable of spe- cific experience. The following is a definition of a problem: the training review dataset is denoted by $Q=o_{1}, o_{2}, \cdots . o_{n}$. Each sure review sample's set of features is recognised by $X$, as well as the associated classification label is defined by $Y$ : reasonable comment and serious comment.

$P$ denotes the likelihood of favorable and unfavorable comments: $P \in[0 \in, 1] . F$ represents the $n * m$ recognizable matrix, $n$ represents the total number of samples, $m$ denotes the average number of features $|\mathrm{p}|$, and $z_{i}$ represented in Equation (10) is the prediction performance of the $i^{\text {th }}$ sample.

$$
z_{i}= \begin{cases}1, & p_{i}>\omega \\ 0, & \text { others }\end{cases}
$$

To examine the efficacy of the optimization method in producing personalized exercise suggestions for students, this publication first employs the precision, recall, and $h_{1}$ indices to assess the suggestion effect; the equation for determining the evaluation identifiers is as in the following.

$$
\begin{aligned}
& \text { Precision }=\frac{\mathrm{QD}}{\mathrm{QD}+\mathrm{FS}}, \\
& \text { recall }=\frac{\mathrm{QD}}{\mathrm{QD}+\mathrm{Fp}} .
\end{aligned}
$$

Recall in Equation (12) is defined to produce personalized exercise suggestions for students, call back or remembrance. An example of recall is someone having an evaluation identifiers in recollection

$$
h_{1}=\frac{2 * \text { precision } * \text { recall }}{\text { precision }+ \text { recall }},
$$

$$
h(s)=\left(\frac{\sum_{i=1}^{n} S l_{i}}{n}\right)\left(\sum_{j=1}^{m} \alpha_{j} h_{j}(S)\right),
$$

where $I$ as according to Honey and Mumford's learning style.

$S l_{i}$ in Equation (14) is the probabilistic requirement index of the correlating application to such a specific learning style $(n=4) . I$ is $j$ the load of criterion $j$ and $h_{j}(S)$ the value.

According to since all evaluation criteria appear to be of similar significance to evaluators, all assessment method weights $=0.25$.

Consider the values $h_{j}(S)$ of recognition and then use assessment methods $(j=1, \cdots, 4)$ using fuzzy triangular 
numbers for $\mathrm{SR}$ systems $\mathrm{SR}_{1}$ as well as $\mathrm{SR}_{2}$.

$$
\begin{aligned}
\mathrm{SR}_{1}= & (1.2000 .7000 .7000 .400) \\
\mathrm{SR}_{2}= & (0.8000 .8000 .6000 .400), \\
\mathrm{SR}_{1}\left(\sum_{j=1}^{m} \alpha_{j} h_{j}(s)\right)= & 0.4 * 1.200+0.3 * 0.700+0.3 * 0.700 \\
& +0.4 * 0.400=0.69 \\
\mathrm{SR}_{2}\left(\sum_{j=1}^{m} \alpha_{j} h_{j}(s)\right)= & 0.4 * 0.800+0.3 * 0.800+0.3 * 0.600 \\
& +0.4 * 0.400=0.62 .
\end{aligned}
$$

Eventually, the $h(S)$ values of appropriateness, recognition, or use of augmented reality technology for specific student $L$ are:

$$
\begin{aligned}
& h(S)=\left(\frac{\sum_{i=1}^{n} S l_{i}}{n}\right)\left(\sum_{j=1}^{m} \alpha_{j} h_{j}(p)\right)=0.3034 * 0.69=0.256 \text { for } \mathrm{SR}_{1}, \\
& h(S)=\left(\frac{\sum_{i=1}^{n} S l_{i}}{n}\right)\left(\sum_{j=1}^{m} \alpha_{j} h_{j}(p)\right)=0.1824 * 0.62=0.163 \text { for } \mathrm{SR}_{2} .
\end{aligned}
$$

It is discovered that there are various quantitative attributes in the evaluation and decision-making of learning programs.

\section{Results and Discussion}

The rapid development of information situations drives the curriculum optimization of the data-driven educational decision-making system, which will inevitably improve teaching quality and optimize the higher education curriculum. It not only diversifies the teaching model but also promotes the reform and development of the traditional curriculum. In this section, the fuzzy logic algorithm has been implemented for evaluating the efficiency of the decision-making process in higher education.

In general, fuzzy logic is being used to simulate human reasoning and cognition. Instead of strictly binary instances of truth, fuzzy logic contains 0 and 1 as extreme situations of reality but with varying degrees of reality in between. Consequently, fuzzy logic is perfect for the following effects: analysis and system for decisions with unknown certainties and inaccurate data-as with speech recognition technologie$s$-and regulating and trying to control machine results based on multiple input and output variables with controllers. In this study, fuzzy logic is used to determine the decision-making system for curriculum optimization. It is highly related to human reasoning and cognition about the curriculum optimization.

Under the data quantity of each data, the record contains ten thousand data, the specified limit of higher education measurement, and decision-making distribution. The vari-

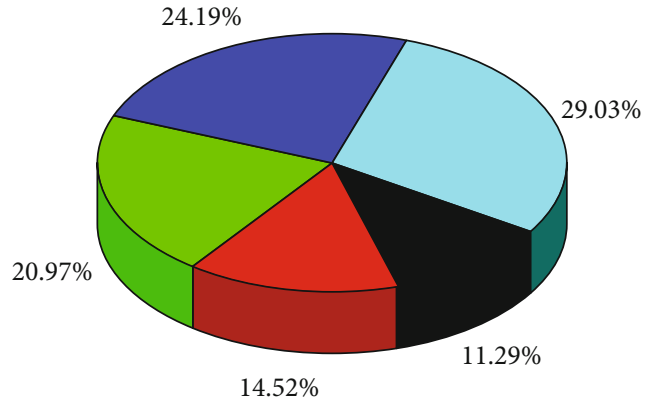

Fuzzy logic using perforrmance analysis for data volume and evaluation and decision-making time

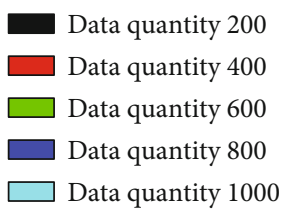

FIgURE 2: Fuzzy logic using performance analysis for data size with evaluation and decision-making time.

ance of evaluation and decision-making prediction error is level when $T$ is 1.7-1.9. The specified level of evaluation and decision-making diffusion can consistently keep the evaluation and decision-making prediction error below $8 \%$. The Euclidian spacing of various classifications of higher education assets is under data quantity 200, 400, 600, and 800 data's specified level of $11.29 \%, 14.52 \%, 20.97 \%$, and $24.19 \%$ higher education resource evaluation, and decisionmaking diffusion is integrated within one class. The new classification can increase the efficiency and precision of data quantity 1000 data's specified level of $29.03 \%$ higher education resource evaluation, but instead, decision-making through data mining, thereby reducing error in higher learning resource evaluation or rather decision-making. Figure 2 depicts the assessment and decision accuracy of higher learning resource management under data analysis (Table 1).

When deciding to apply to the learning system, the higher education evaluation time (s) and decision-making method based on the data mining will efficiently possess intelligent parallel evaluation and decision-making.

The connection between percentage, storage space of higher education evaluation, and decision-making in the context of data extraction is made. One can see that the increased number of research methodology (Figure 3) has little effect on the collection area that is covered by them, demonstrating that the evaluation and decision-making techniques of higher education under data mining were also organized and feasible (Table 2).

A data mining-based education evaluation and decisionmaking method will effectively carry out similar intelligent assessment and decision-making when implemented to an education platform. Also, make big data size (10000) evaluation and decision-making of all school information into a tool for evaluation feedback as in Figure 4. Educational leaders and teachers could indeed recognize the inadequacies of students' knowledge from huge data evaluation or rather decision- 
TABLE 1: Relationship between data volume and evaluation and decision-making time.

\begin{tabular}{lc}
\hline Data quantity (ten thousand) & Evaluation and decision time (s) \\
\hline 200 & 7 \\
400 & 9 \\
600 & 13 \\
800 & 15 \\
1000 & 18 \\
\hline
\end{tabular}

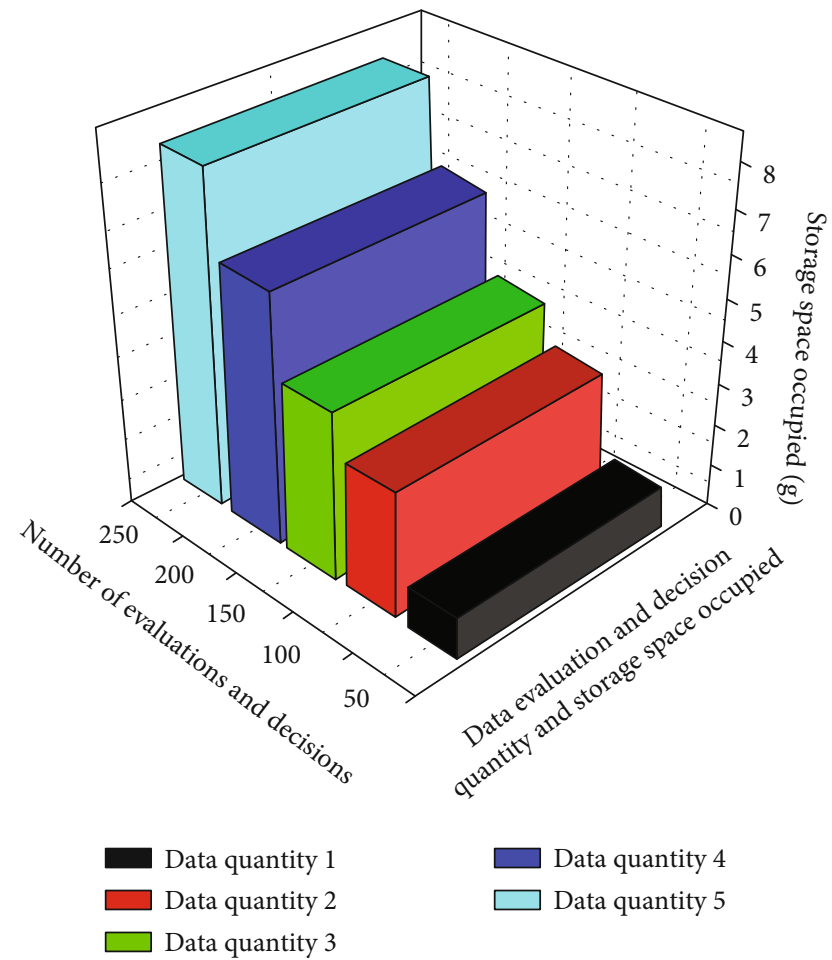

Figure 3: Data evaluation with decision quantity and storage space occupied performance analysis.

TABLE 2: Analyze the result data analysis and decision-making occupied quantity and storage space.

\begin{tabular}{lc}
\hline $\begin{array}{l}\text { The total number of evaluations and } \\
\text { decisions }\end{array}$ & $\begin{array}{c}\text { Occupied storage } \\
\text { space }\end{array}$ \\
\hline 100 & 2 \\
200 & 4 \\
300 & 5 \\
400 & 8 \\
500 & 9 \\
\hline
\end{tabular}

making evaluation of the student. Personalized teaching is decided to carry out for students based on students' vulnerabilities that further enhance the educational level.

Figure 5 clearly shows that the precision of higher education measurement and decision-making under data mining changes with time. The longer the period, the larger the accuracy of higher learning measurement and decision-mak-

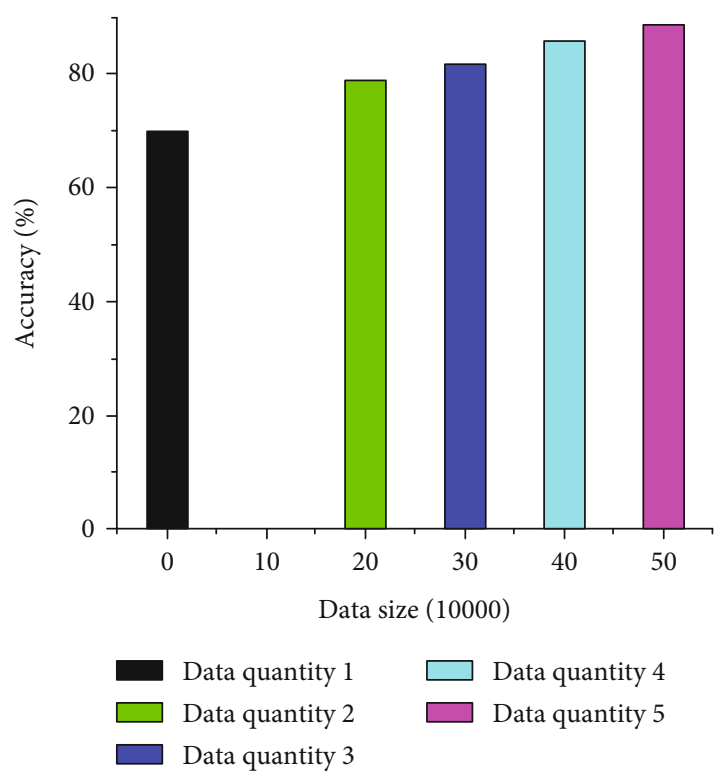

Figure 4: The rate of error in higher education evaluation data size (10000) as well as decision-making process.

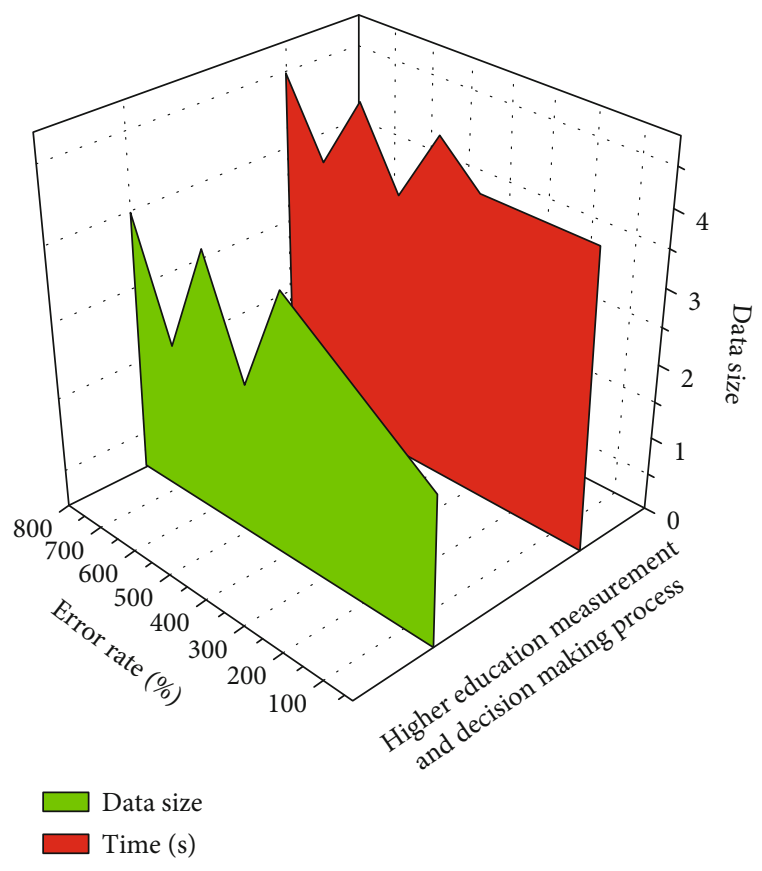

FIgURE 5: The performance analysis rate of error in higher education measurement and decision-making process.

ing, which has been guaranteed to the greatest extent possible. It also validates the overall efficiency of the data-driven higher education analysis as well as decision-making technique.

Educational leaders and teachers can recognize the weak points of students' knowledge from big data measurement and decision-making analysis of a classroom. Individual teaching is decided to carry out for students depending on the weak spots of students' understanding, which further enhances the teaching level (Figure 6). 


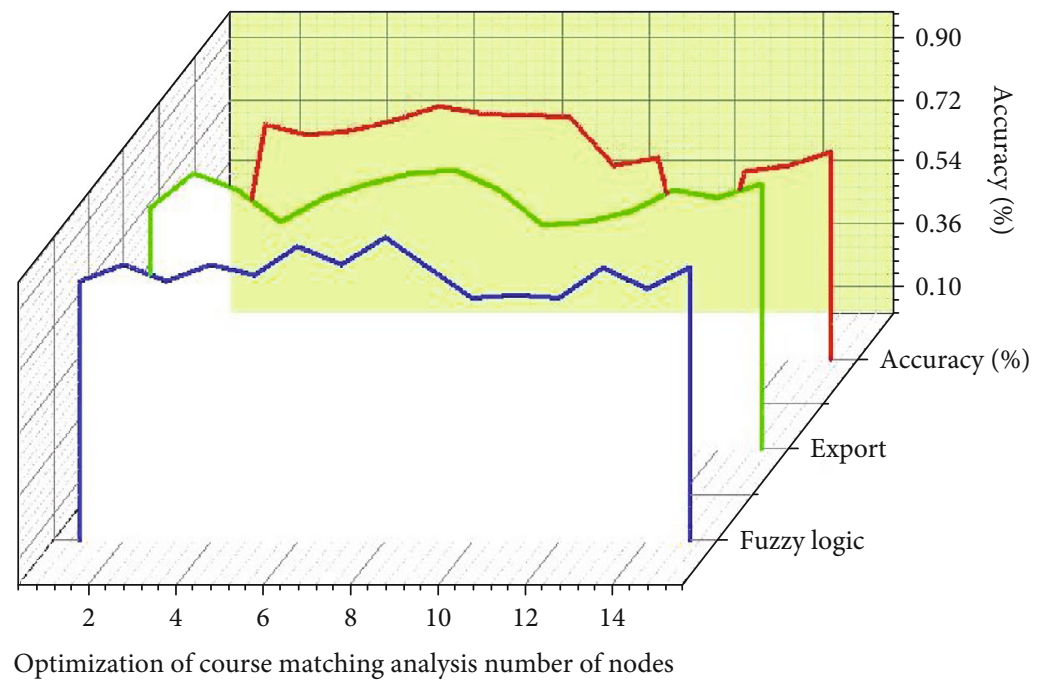

FIgURE 6: Optimization of course matching analysis of number of nodes.

The proposed algorithm tends to meet the needs of different types of learners, improve students' performance in the learning process, and promote more scientific management decisions in the curriculum reform of colleges and universities, improving the quality of higher education.

\section{Conclusions}

Based on the data-driven education decision-making system, the study integrates the curriculum optimization system of higher education, constructs the model of curriculum optimization, and uses the system. Various algorithms are set in the model to optimize the current curriculum and test the results of the application of the system. The system can summarize the existing problems of the current courses to be optimized, and the system can automatically define the indexes according to the optimization index definition system. In the subsequent data analysis and processing process, the reliability analysis, validity analysis, difference analysis, and the indexes determined by the system can pass the test in the corresponding algorithm. This study concludes that applying the data-driven education decision-making system to the curriculum optimization of higher education is feasible. After the curriculum optimization system is integrated into the traditional education decision-making system, the integrated system can optimize various courses according to the modules in the system and automatically generate the curriculum optimization report for the decisionmaking organization. The new data based on the optimization model of the curriculum system have such advantages, such as efficiency, convenience, accuracy, and timeliness, which are not achieved by the traditional one. Study's shortcomings are as follows: (1) there is no research on the physical stability of the system; (2) the ability of data is weak in processing the state of large systems, also the uncertainty between the optimization of many unrelated complex field courses and the development experience of course optimization. Based on the above shortcomings, it is believed that colleges and universities should develop more data-driven educational decision-making systems to optimize the current curriculum and promote the quality of higher education. As a future enhancement in this research, expressions or analysis in concerning to Bloom's Taxonomy and ABET Criteria in Student's Learning comes will be performed. This analysis will further aid in the improvement in the datadriven-based decision-making system.

\section{Data Availability}

The data that support the findings of this study are available upon request.

\section{Conflicts of Interest}

The authors declare that they have no conflicts of interest.

\section{References}

[1] Z. H. Chen, "The optimization of applied statistics curriculum system to adapt to the era of big data," Journal of Science and Technology Economics, vol. 28, no. 10, p. 105, 2020.

[2] Y. Z. Luo, J. Zhang, X. R. Li, and G. R. Li, "Educational management and decision-making optimization from the perspective of big data," China Management Information Technology, vol. 22, no. 5, pp. 162-164, 2019.

[3] D. J. Fu, "The influence of educational big data on teaching decision-making and optimization strategies," Journal of Hubei Institute of Adult Education, vol. 24, no. 2, pp. 90-93, 2018.

[4] H. B. Li and B. L. Wan, "Design and implementation of an auxiliary decision-making system for education special planning based on spatio-temporal big data and cloud platform," Beijing Surveying and Mapping, vol. 34, no. 7, pp. 905-909, 2020.

[5] T. R. Bi and X. Wang, "The application of data-driven decision support system in the quality management of college education," China Education Informatization, vol. 4, no. 3, pp. 60 $62,2016$. 
[6] A. Radhika and M. S. Masood, "Effective dimensionality reduction by using soft computing method in data mining techniques," Soft Computing, vol. 25, no. 6, pp. 4643-4651, 2021.

[7] S. Ebiesuwa, T. Omolara, and A. A. Yinka, "The need for domain expert in data mining application," Journal of Theoretical and Applied Information Technology, vol. 99, no. 3, pp. 630-650, 2021.

[8] C. Zheng and W. Zhou, "Research on information construction and management of education management based on data mining," Journal of Physics: Conference Series, vol. 1881, no. 4, article 042073, 2021.

[9] K. Guts, A. A. Senkovskaya, and I. I. Furayeva, "Modelling and construction of curriculum optimization algorithms in order to improve the effectiveness of management of the educational process," Journal of Physics: Conference Series, vol. 1791, no. 1, article 012074, 2021.

[10] S. Lokasree, "Data analysis and data classification in machine learning using linear regression and principal component analysis," Turkish Journal of Computer and Mathematics Education (TURCOMAT), vol. 12, no. 2, pp. 835-844, 2021.

[11] A. Saxena and V. Rajpoot, "A comparative analysis of association rule mining algorithms," IOP Conference Series Materials Science and Engineering, vol. 1099, no. 1, article 012032, 2021.

[12] J. Liu and B. Wen, "Construction and optimization of educational technology course knowledge network," International Journal of Information and Education Technology, vol. 10, no. 9, pp. 694-703, 2020.

[13] E. Kardoyo, "Development of e-learning management model for teaching system at the police academy," Turkish Journal of Computer and Mathematics Education (TURCOMAT), vol. 12, no. 5, pp. 188-196, 2021.

[14] Q. Y. Wang and A. C. Zou, "Using the basic status database of undergraduate teaching to carry out the reform of professional ability formative curriculum construction based on the new engineering concept," Education Modernization, vol. 7, no. 14 , pp. 15-17, 2020.

[15] X. H. Xu and X. Y. Guo, "Construction and optimization of online courses in colleges and universities based on 'Internet+'," Educational Modernization, vol. 5, no. 24, pp. 100$102,2018$.

[16] Y. Chen, "The optimization strategy of college curriculum evaluation mode with the goal of promoting teaching," Heilongjiang Science, vol. 10, no. 23, pp. 28-29, 2019.

[17] K. Kajita, A. Kiuchi, E. Hasegawa, K. Park, Y. Kawato, and A. Nakagawa, "Current status of physical education in liberal arts higher education courses at colleges and universities in Japan," Taiikugaku kenkyu (Japan Journal of Physical Education, Health and Sport Sciences), vol. 63, no. 2, pp. 885-902, 2018.

[18] G. White, "The application of ethical themes for responsible data-driven decision making in education," in Responsible Analytics and Data Mining in Education, pp. 229-244, Routledge, 2018.

[19] K. Schneider, "Taking data-driven decision making to the next level," in Institutional Research Initiatives in Higher Education, pp. 100-115, Routledge, 2017.

[20] T. Price, "Big data, dashboards, and data-driven educational decision making," in Encyclopedia of Strategic Leadership and Management, pp. 1314-1325, IGI Global, 2017.
[21] D. Ballou, L. Heitger, and D. Stoel, "Data-driven decisionmaking and its impact on accounting undergraduate curriculum," Journal of Accounting Education, vol. 44, pp. 14-24, 2018.

[22] A. Pickup, "Toward a historical ontology of the infopolitics of data-driven decision-making (DDDM) in education," Educational Philosophy and Theory, pp. 1-12, 2021.

[23] D. Bertsimas and A. Thiele, "Robust and data-driven optimization: modern decision making under uncertainty," in Models, Methods, and Applications for Innovative Decision Making, pp. 95-122, INFORMS, 2006.

[24] T. Richardson, "Data-driven decision making and dynamic planning: a school leader's guide20085Paul G. Preuss. Datadriven decision making and dynamic planning: a school leader's guide. Eye on Educations, 2007. \$34.95 160 pp. ISBN 978-1-59667-070-9," Journal of Educational Administration, no. 5, pp. 663-665, 2008. 